\title{
Neurobehavioural effects of occupational exposure to lead
}

\author{
A M Williamson AND R K C TEO \\ From the Division of Occupational Health, Department of Industrial Relations, New South Wales Government, \\ Sydney, Australia
}

\begin{abstract}
A set of neurobehavioural tests selected on the basis of information processing theory was used to study the effect of low level occupational lead exposure on 59 lead workers compared with a matched control group of the same number. Only one of the lead exposed group had a blood lead concentration above the current threshold limit value of $3.81 \mu \mathrm{mol} / 1$ at the time of testing (mean $2.36 \mu \mathrm{mol} / 1$, range $1 \cdot 19-3.92 \mu \mathrm{mol} / \mathrm{l})$ and none had been detected above that level in the previous three years. Nevertheless, most neurobehavioural functions tested showed some impairment in the lead workers. Visual sensory function was affected and, perhaps as a consequence, sustained attention and psychomotor tasks were performed more slowly by the lead exposed group. Cognitive functions were also impaired, with sensory store memory, short term memory, and learning abilities all showing deficits in lead workers. Such cognitive deficits may also be partly due to initial degradation of the visual input. Long term memory performance compared equally with control levels possibly because of development of a compensatory strategy such as rehearsal by the lead exposed subjects. Multiple linear regression analysis relating to lead workers test performance and their lead exposure showed that performance on the sensory store memory test alone was significantly related to exposure. This was probably due to the homogeneity of the lead exposed group with regard to blood lead concentrations and the use of blood lead as a measure of chronic lead exposure.
\end{abstract}

It is now hardly disputed that inorganic lead exposure can affect the nervous system or that lead exposure well within the levels obtained through occupational exposure may have serious consequences for behaviour. For example, lead exposure producing blood lead concentrations below $2.86 \mu \mathrm{g} / 1$ had been shown to impair peripheral nerve function ${ }^{12}$ and psychomotor $^{3-7}$ and cognitive functions. ${ }^{6-11}$

Unfortunately, however, there is little uniformity in the range of tests used in about 30 studies dealing with this topic in recent years. Most studies have focused on peripheral nerve function with central nervous function being implied from psychomotor tasks. When central nervous function has been investigated more specifically, tests from larger batteries such as the Wechsler adult intelligence test (WAIS) ${ }^{\mathbf{1 2}}$ or Wechsler memory test ${ }^{13}$ have been used. While these tests are well standardised, they probably lack sensitivity to detect the more subtle effects of low level lead exposure. In addition, tests such as vocabulary, arith-

Accepted 9 September 1985 metic, information, and similarities from the WAIS probably reflect more about educational experience and literacy than the action of a neurotoxin, especially at low levels.

This problem may also explain the inconsistencies in obtained results. Even where identical tests were used in different studies, the results were not replicated consistently. ${ }^{14}$ Possible lack of sensitivity in tests used and differences in exposure levels between and within studies account for this.

The present study was designed to overcome these problems by examining the information processing abilities of a group of lead workers for whom estimates of present and past lead body burden were available and comparing them with a similar nonexposed control group.

Information processing theory, as a method of describing nervous system function, ${ }^{15}$ provides a logical framework for the selection and interpretation of performance tests. This approach proved to be useful in studying the behavioural effects of mercury exposure $^{16}$ and may be of value in identifying early 
deficits of nervous system function caused by other heavy metals commonly used in the workplace.

As no other study known to us has used the information processing theoretical approach to the study of lead exposed workers, it was decided to test the efficacy of the behavioural tests on a sample of workers who had low level lead exposure detected by blood assay.

\section{Methods}

\section{SUBJECTS}

Fifty nine lead workers were tested: 31 were employees in a battery manufacturing company and the remainder worked in secondary lead smelting. All lead workers were men aged between 18 and 65 and none had ever been treated for lead intoxication. A group of 59 non-exposed individuals was used for comparison purposes, being matched so far as possible with the lead workers on such factors as age, type of job, duration of employment, education level, and consumption of cigarettes and alcohol. The control group was predominantly men (17\% were women) and had no history of any toxic exposure.

\section{EXPOSURE MEASURES}

Measures of lead exposure were taken for the lead group. These included blood lead results taken at the time of testing and, in most cases, results from the past three years were available and were averaged for each year. Blood was obtained by venepuncture $(10 \mathrm{ml})$ and analysed by the division of analytical laboratories, NSW Department of Health, using an atomic absorption method.

An attempt was made to gauge the extent of direct exposure to lead by asking each exposed person about the duration of exposure per day and the number of years of exposure. Direct contact was then expressed in terms of the number of contact hours.

\section{BEHAVIOURAL TESTS}

The tests have been described in detail elsewhere. ${ }^{16}$ Briefly, the tests were as follows:

1 Critical flicker fusion-A perceptual test in which a critical flicker fusion threshold is obtained for each eye.

2 Vigilance-A sustained attention task in which the subject is required to track the illumination sequence of five lights and the infrequent $(10 \%)$ occurrence of two lights illuminated simultaneously. The task was performed for 20 minutes. The number of single and double targets tracked, the number of targets missed, and the number of gaps or occasions when reaction time exceeded twice the previous mean reaction time (taken over 64 responses) were taken for every five minutes during the test.
3 Simple reaction time-A psychomotor task measuring the speed of response to a simple single digit display.

4 Visual pursuit-A psychomotor task requiring the subject to track a moving light within a circular pathway at speeds of $15 \mathrm{rpm}, 30 \mathrm{rpm}$, and $15 \mathrm{rpm}$ in three separate one minute trials. Total time on target was recorded for each trial.

5 Hand steadiness-A psychomotor task in which the subject held a stylus in a $5 \mathrm{~mm}$ diameter hole between two metal plates with an outstretched arm, keeping as still as possible for one minute. A buzzer sounded whenever the subject was off target. The number and duration of touches on upper and lower plates were recorded independently for three consecutive 20 second periods.

6 Sensory store memory-This first memory stage was investigated using tachistoscopic presentation of pairs of letters presented to the central and peripheral visual fields for 150,300 , or 450 msecs. A cue card which followed and was visible for 150 msecs designated the position of the letter pairs to be recalled by the subject. The number of letters correctly recalled was recorded. Three trials were presented in each position for each stimulus speed.

7 Sternberg memory test-A short term memory test in which subjects were asked to remember a varying number of single digits $(2,3,4$, or 5 digits $)$ and then respond positively (Yes button) or negatively (No button) when each of a random set of digits was presented to them. Speed of response was measured for each digit set and for positive or negative responses.

8 Paired associates, short term memory testPairs of three letter words (trigrams) were presented once, then the first member of each pair. The subject was required to write down the matching member of the pair. The sequence was repeated with trigrams in random order each time until all five trigrams were recalled correctly. The number of trigrams correctly recalled on the first trial and the number of trials to criterion were recorded.

9 Paired associates, long term memory-Subjects were required to recall the trigrams learned earlier (about 90 minutes before) when presented with the first member of each pair shown in the short term memory test.

10 Procedure-All testing took about 90 minutes to complete. This included time for test familiarisation and practice before any measurements were taken. Each session began with the completion of a demographic questionnaire.

Critical flicker fusion (CFF) tests were performed at the beginning and end of testing to check for fatigue effects over the time of testing. The paired associate short term memory test was conducted next in 
Table 1 Details of exposure for the lead group showing blood lead concentrations and total exposure times at the time of neurobehavioural testing

\begin{tabular}{|c|c|c|c|c|c|c|}
\hline \multicolumn{7}{|c|}{ Percentage of group in each range } \\
\hline \multicolumn{7}{|c|}{ Blood lead concentrations ( $\mu \mathrm{mol} / \mathrm{l}$ ) } \\
\hline $8^{<1 \cdot 5}$ & $\begin{array}{l}1 \cdot 51-2 \cdot 0 \\
25\end{array}$ & $\begin{array}{l}2 \cdot 01-2 \cdot 5 \\
31\end{array}$ & $\begin{array}{l}2 \cdot 51-3 \cdot 0 \\
24\end{array}$ & $\begin{array}{l}3 \cdot 01-3 \cdot 5 \\
7\end{array}$ & $3 \cdot 51-4 \cdot 0$ & $\begin{array}{l}\text { Mean (and standard deviation) } \\
2 \cdot 37(0.64)\end{array}$ \\
\hline $\begin{array}{l}0-500 \\
15\end{array}$ & $\begin{array}{l}501-1000 \\
17\end{array}$ & $\begin{array}{l}1001-5000 \\
22\end{array}$ & $\begin{array}{l}\text { Tota } \\
5001-10000 \\
22\end{array}$ & $\begin{array}{l}\text { sposure (h) } \\
10001-15000 \\
12\end{array}$ & $\begin{array}{l}>15 \\
12\end{array}$ & $\begin{array}{l}\text { Mean (and standard deviation) } \\
8109 \cdot 2(12435 \cdot 7)\end{array}$ \\
\hline
\end{tabular}

order to maximise the time interval between learning and trigrams and the long term memory (LTM) test for them. Consequently, the LTM test occurred just before the final CFF test. The vigilance test was performed in the latter part of the test sequence (just before LTM) since it was relatively fatiguing. The remainder of the tests were administered in a random order.

\section{Results}

The lead exposed and control groups were not significantly different in age (median $=33.47$ years for lead and 29.00 years for control groups $\chi^{2}{ }_{5}=$ $10 \cdot 25, \mathrm{NS})$ type of job $\left(\chi_{3}{ }_{3}=5 \cdot 06, \mathrm{NS}\right)$, time on job (median $=2.08$ years for lead and 2.18 years for controls, $\chi^{2}{ }_{4}=3.93$, NS) or education level (median = 10.59 years for lead and 11.12 years for controls, $\chi_{3}^{2}$ $=6.56$, NS). There was no significant difference between the percentage who smoked cigarettes in either group (59.3\% for lead and $44.07 \%$ for controls, $\chi^{2}{ }_{1}$ $=2 \cdot 74$, NS) or the amount smoked a day (median $=$ 13.8 cigarettes for lead and 16.7 for control groups, $\chi^{2}{ }_{3}=6.95$, NS) The number of individuals consuming alcohol in each group was not significantly different $\left(57.6 \%\right.$ for lead and $62.7 \%$ for controls, $\chi^{2}{ }_{1}$ $=0.33$, NS) nor was the amount consumed in the past 24 hours (median $=54 \mathrm{~g}$ for lead and $35 \mathrm{~g}$ for control groups, $\left.\chi^{2}{ }_{4}=7 \cdot 70, \mathrm{NS}\right)$. All subjects had adhered roughly to their usual sleep waking pattern and most had consumed food at the last meal (usually breakfast).

Table 1 shows the exposure details for the lead workers. Blood lead concentrations for the test day were similar to the pattern of results over the past

Table 2 Results of the critical flicker fusion test showing mean thresholds $(\mathrm{Hz})$ and standard deviations for lead exposed and control groups on the first and second tests

\begin{tabular}{lll}
\hline & Lead exposed & Controls \\
\hline 1st test & $35 \cdot 73(4 \cdot 77)$ & $37 \cdot 23(4 \cdot 75)$ \\
2nd test & $35 \cdot 19(4 \cdot 76)$ & $36 \cdot 48(5 \cdot 73)$ \\
\hline
\end{tabular}

three years $(2 \cdot 36,2 \cdot 36$, and $2 \cdot 32 \mu \mathrm{mol} / 1$ for years 1,2 , and 3). Most workers had fairly short term exposure to lead with nearly one third being exposed for less than 1000 hours. Only one worker had blood lead concentrations above the current threshold limit value $(3.81 \mu \mathrm{mol} / \mathrm{l})$ at any time during the study period. The group therefore was within the currently accepted limits of exposure.

\section{BEHAVIOURAL TESTS}

Analysis of variance ( 2 factor, repeated measures on one factor) showed that CFF thresholds (table 2) were significantly lower in lead exposed than controls (group main effect $\mathrm{F}_{1,234}=5.14, \mathrm{p}<0.05$ ). There was also a significant decrease in threshold between first and second test (test main effect, $F_{1,234}=8.44$, $\mathrm{p}<0.01$ ) but to the same degree in lead exposed and control groups (interaction effect, $F_{1.234}=0 \cdot 22$, NS).

Sustained attention (fig 1 ) was not greatly affected by lead exposure as shown by analysis of variance ( 3 factor with repeated measures on 2 factors). Performance over time in the vigilance task was comparable in both groups in terms of the number of single target errors (group main effect $F_{1,116}=3 \cdot 28$, NS), double target errors (group main effect $F_{1,116}=$

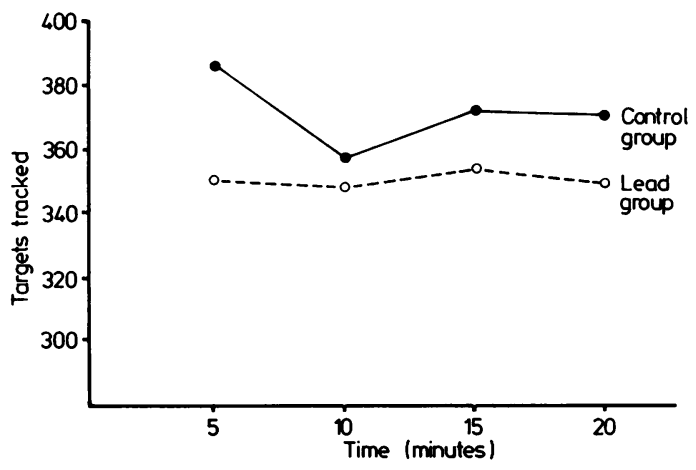

Fig 1 Results of vigilance test for lead exposed and control groups showing mean number of targets tracked at each five minute period. 


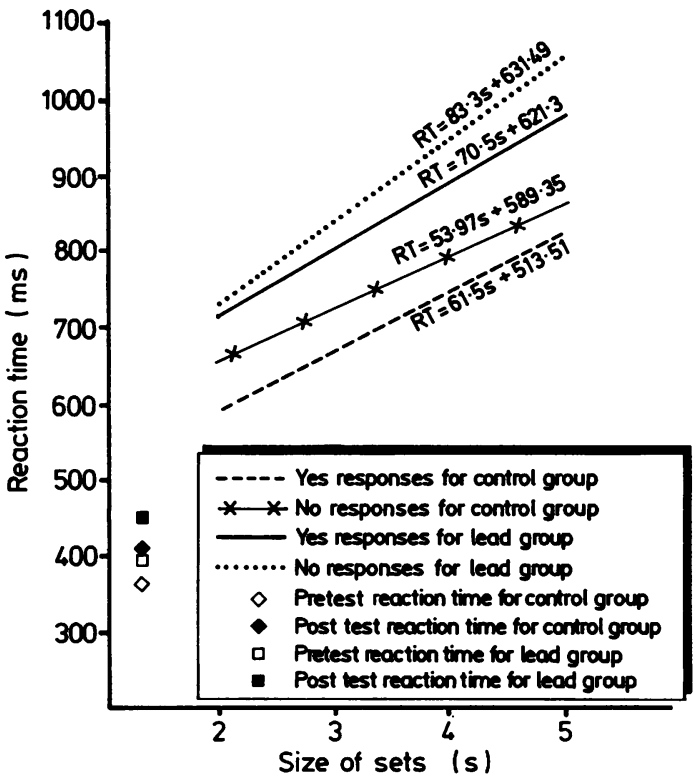

Fig 2 Sternberg short term memory test results showing lines of best fit for positive (Yes) and negative (No) response tests for both lead exposed and control groups. Pretest and posttest reaction times (means) are also shown for lead exposed and control groups.

$0.21, \mathrm{NS}$ ), and gaps in continuity of performance (group main effect $F_{1,116}=0 \cdot 27, N S$ ). Analysis of the number of targets tracked, however, showed differences between the groups. Whereas there was no significant main effect between the groups $F_{1,116}=$ 3.60 , NS), there was a significant time period main effect $F_{3,348}=3.97, p<0.01$ ) as well as a significant interaction between group and time period (five minute block) $\mathrm{F}_{3,348}=2.82, \mathrm{p}<0.05$ ). Post hoc Scheffe' tests showed that the lead group tracked significantly fewer targets than controls during the first and final five minute periods and that the control group showed significantly lower tracking rates in the second time block than at any other time. The lead group showed no such decrease in tracking rate.

Simple reaction time (fig 2) was significantly slower

Table 3 Visual pursuit test results showing means and standard deviations over one minute test period

\begin{tabular}{|c|c|c|}
\hline & \multicolumn{2}{|c|}{ Time on target (secs) } \\
\hline & Lead exposed & Control \\
\hline $\begin{array}{l}\text { Slow tracking (1st test) } \\
\text { (15 rpm) } \\
\text { Slow tracking (2nd test) }\end{array}$ & $24.08(7 \cdot 48)$ & $26.47(9.08)$ \\
\hline $\begin{array}{l}(15 \mathrm{rpm}) \\
\text { Fast tracking }(30 \mathrm{rpm})\end{array}$ & $\begin{array}{r}23.47(8.04) \\
6.57(3.29)\end{array}$ & $\begin{array}{c}27.99(11.04) \\
8.76(4.59)\end{array}$ \\
\hline
\end{tabular}

in the lead exposed group, compared with controls (2 factor ANOVA with repeated measures on one factor, group main effect $F_{1,116}=4.74, p<0.05$ ). Both groups showed significant decreases in reaction speed after extended testing with the apparatus (retest main effect $F_{1,116}=52.94, p<0.001$ ) but to the same extent in each group (interaction $F_{1,116}=1.03$, NS).

Analysis of variance ( 2 factor with repeated measures on one factor) of the visual pursuit results (table 3) showed that the lead exposed group was significantly slower than controls at both fast and slow tracking speeds (group main effect $F_{1,116}=$ $5.68, p<0.05$ ). Performance for both groups slowed significantly when required to track at the faster speed (speed main effect $F_{2,232}=660.1, p<0.001$ ) but to the same degree in each group (interaction $\mathbf{F}_{\mathbf{2 , 2 3 2}}=$ $2 \cdot 58, \mathrm{NS})$.

The hand steadiness test results were analysed by two 3 factor ANOVAs (repeated measures on two factors). Significantly more off target touches (table 4) were made by lead exposed workers than controls (group main effect, $F_{1,116}=9.05, p<0.01$ ). Off target touches were significantly more frequent to the bottom plate in both groups (plate main effect $F_{1,116}$ $=44.79, \mathrm{p}<0.001)$ and to the same extent in both groups $\left(F_{1,116}=3.05, N S\right)$. There was no significant difference between lead and control groups in off target touches over the period of the test (group main effect, $F_{2,232}=1 \cdot 28$, NS) nor was any interaction involving the time period statistically significant.

The time spent off target (table 4) was also significantly longer for the lead exposed group (group main effect $F_{1.116}=5.09, p<0.05$ ). Again the lower plate was the site of most time off target for both groups (plate main effect $F_{1,116}=36.69$, $p<0.01$ ) and again to the same extent in both groups (interaction $F_{1,116}=2 \cdot 62$, NS). There was no significant main effect of time period $\left(F_{2,232}=0 \cdot 17, N S\right)$. There was, however, a significant interaction between the group and time period $\left(\mathrm{F}_{2.232}=418.71, \mathrm{p}<0.001\right)$ and a significant three way interaction (group $\times$ plate $\times$ time period $\left.F_{2,232}=316.13, p<0.001\right)$. Subsequent Scheffe' tests showed that the only significant differences were between lead and control groups and upper and lower plates.

Analysis of variance ( 3 factor with two repeated measures) of the sensory store memory test results (table 5) showed significantly poorer memory performance in the lead exposed group (group main effect, $F_{1,98}=7 \cdot 20, p<0.01$ ). The other main effects were also significant (speed of presentation, $F_{2,196}=$ $34.46, \mathrm{p}<0.01$ and part of visual field, $\mathrm{F}_{2,196}=$ $172.62, p<0.01$ ) indicating that performance improved significantly as presentation speed increased and that central visual field performance was significantly superior to that in the periphery. 
Table 4 Results of the hand steadiness test for lead exposure and control groups showing means and standard deviations for each consecutive 20 second test period of 60 second test

\begin{tabular}{|c|c|c|c|c|c|c|}
\hline & \multicolumn{3}{|c|}{ Lead exposed ( 20 second time period) } & \multicolumn{3}{|c|}{ Control (20 second time period) } \\
\hline $\begin{array}{l}\text { Off target touches: } \\
\text { Upper plate } \\
\text { Lower plate }\end{array}$ & $\begin{array}{l}23.44 \\
(15.64) \\
31.41 \\
(18.87)\end{array}$ & $\begin{array}{c}24 \cdot 47 \\
(15 \cdot 48) \\
30 \cdot 51 \\
(16.45)\end{array}$ & $\begin{array}{c}23.24 \\
(15.43) \\
30.54 \\
(16.43)\end{array}$ & $\begin{array}{c}19 \cdot 53 \\
(10 \cdot 47) \\
23 \cdot 08 \\
(12.66)\end{array}$ & $\begin{array}{c}18.27 \\
(8.86) \\
22.64 \\
(10.07)\end{array}$ & $\begin{array}{c}17 \cdot 73 \\
\left(\begin{array}{c}9 \cdot 01) \\
22 \cdot 29 \\
(10 \cdot 27)\end{array}\right.\end{array}$ \\
\hline $\begin{array}{l}\text { Time off target (secs): } \\
\text { Upper plate }\end{array}$ & $\begin{array}{l}1.97 \\
(1.27) \\
2.94 \\
(1.87)\end{array}$ & $\begin{array}{l}2 \cdot 14 \\
(1.33) \\
2.95 \\
(1.70)\end{array}$ & $\begin{array}{l}2.00 \\
(1.26) \\
2.80 \\
(1.53)\end{array}$ & $\begin{array}{l}1.78 \\
(1.41) \\
2.37 \\
(1.82)\end{array}$ & $\begin{array}{l}1.71 \\
(1.11) \\
2.15 \\
(1.42)\end{array}$ & $\begin{array}{l}1.65 \\
(1.32) \\
2 \cdot 14 \\
(1.53)\end{array}$ \\
\hline
\end{tabular}

Figure 2 shows the results of the Sternberg short term memory test. Lines of best fit were calculated for speed of response against the size of the memory set for both positive (actively remembered or "Yes" items) and negative (items not in memory set or "No" items) memory sets. Comparison of the slopes of the lines for lead and control groups showed that for both types of memory set, the cognitive component of the task took significantly longer in the lead exposed group (positive set, $t_{1,16}=4.46, p<0.001$; negative set, $\left.t_{1,16}=17.49, p<0.001\right)$. Analysis of the intercepts also showed significantly slower performance by lead workers (positive set, $\mathrm{t}_{1,16}=14.45, \mathrm{p}<0.001$; negative set, $\mathrm{t}_{1,16}=5.72, \mathrm{p}<0.001$ ).

The performance of the lead exposed group was significantly poorer than that of controls in the paired associates short term memory test (table 6). Not only did the lead workers recall significantly fewer trigrams on the first round $\left(\mathrm{t}_{1.16}=5.68, \mathrm{p}<0.001\right)$ but they took significantly more trials to reach the criterion of all correct $\left(t_{1,16}=2.83, p<0.01\right)$. In addition, more than half of the lead group $(64 \cdot 2 \%)$ failed to reach criterion, compared with $13.8 \%$ of the control group. As a consequence, analysis of performance on the

Table 5 Results of the sensory store memory test showing means and standard deviations for each speed of presentation and part of visual field comparing lead exposed and control groups

\begin{tabular}{llll}
\hline $\begin{array}{l}\text { Speed of } \\
\text { presentation }\end{array}$ & $\begin{array}{l}\text { Area of } \\
\text { visual field }\end{array}$ & $\begin{array}{l}\text { Lead } \\
\text { exposed }\end{array}$ & Control \\
\hline \multirow{2}{*}{$150 \mathrm{msec}$} & Left & $1.42(1.44)$ & $2.24(1.85)$ \\
& Centre & $3.08(1.90)$ & $4.22(1.59)$ \\
& Right & $0.96(1.34)$ & $1.40(1.72)$ \\
$300 \mathrm{msec}$ & Left & $1.8(1.51)$ & $2.12(1.63)$ \\
& Centre & $4.16(1.58)$ & $4.58(1.30)$ \\
& Right & $1.46(1.63)$ & $2.06(1.65)$ \\
& Left & $1.86(1.65)$ & $2.38(1.86)$ \\
$450 \mathrm{msec}$ & Centre & $4.2(1.60)$ & $4.52(1.63)$ \\
& Right & $1.82(1.82)$ & $2.84(2.05)$ \\
\hline
\end{tabular}

long term memory section of the paired associates test was carried out on a much reduced lead group sample (table 6). Of those who completed the first part of the test to criterion, there was no significant difference in long term memory for lead or control groups $\left(t_{75}=\right.$ $0 \cdot 48, \mathrm{NS})$.

\section{RELATIONS BETWEEN BEHAVIOUR AND}

EXPOSURE

Multiple regression analysis failed to show any association between measures of exposure and performance with the exception of sensory store memory (speed $=150$ msecs) which had a low but significant correlation with blood lead concentrations in the first year of the study $(r=-0.27, p<0.02)$.

\section{Discussion}

Clearly the performance of lead exposed workers on a range of neurobehavioural tests was poorer than would be expected from non-exposed workers. In addition, general arousal, as measured by the CFF test, was clearly depressed under conditions of lead exposure.

It is argued that the CFF threshold is a measure of cortical arousal ${ }^{1718}$ but it is just as likely to reflect retinal or intermediate visual pathway function. ${ }^{19}$ Findings of a decrease in visual sensitivity in lead workers pointing to damage of central and peripheral optic nerve fibres ${ }^{20}$ supports the latter argument.

Table 6 Paired associates memory test results for both short term (STM) and long term (LTM) memory tests. Means and standard deviations comparing lead exposed and control groups

\begin{tabular}{lcc}
\hline & Lead exposed & Control \\
\hline No correct on first test (STM) & $0.72(0.92)$ & $2 \cdot 19(1.59)$ \\
Trials to criterion* & $3.74(1.29)$ & $2.81(1.42)$ \\
\% Completing to criterion & 45.8 & 84.2 \\
No correct at end of test (LTM) & $3.01(1.64)$ & $3.18(1.47)$ \\
\hline
\end{tabular}


That study, ${ }^{20}$ however, failed to find significantly lower CFF thresholds in lead workers, but this could have been due to differences in measurement technique especially since a further study ${ }^{21}$ also found reductions in CFF threshold using the same apparatus and method as was used in the current study.

Whatever the reason for lowered CFF thresholds, information processing theory suggests that if CFF thresholds are lowered other functions will also show effects. With sensory system deficits, it may be argued that the same amount of information may not be available for processing. The results of the remaining tests suggest that this may be so.

Performance accuracy over time in the vigilance task was comparable in both groups. The lead exposed group, however, tracked fewer targets for at least half of the task but kept up a consistent, if lower, performance level. By contrast, controls showed a significant decrease in tracking rate but only for the second five minute block. As the test was self paced, the lead exposed group performed the tracking task consistently more slowly than controls. Impaired visual function or arousal, or both, might be at least partially responsible for this slowing. It is possible that to attain accurate performance in this task, lead exposed individuals had to track more slowly.

Simple and complex psychomotor tests also showed impairments. Performance of reaction time and visual pursuit, both of which rely on visual sensory input, was significantly slower in the lead group; again, possibly caused by degradation of visual input.

In the hand steadiness test poorer psychomotor performance was evident in increased tremor in the lead exposed group. As auditory and visual feedback was provided in this test it might be predicted that lead workers should not show a performance deficit. The dominance of visual control over motor movement and the lack of specificity of auditory feedback in this task (telling you only whether or not you are off target, not your actual location) were likely reasons for performance being poor regardless of the additional feedback.

Naturally, proprioceptive feedback would also be influencial, especially in the hand steadiness test, but it too failed to produce normal performance in lead exposed workers. Findings from several previous studies showed slowed sensory and motor nerve conduction velocities ${ }^{22} 23$ in lead workers with comparable blood lead concentrations to those seen in this study. This could possibly reduce proprioceptive feedback and increase movement time and therefore be an additional factor in the slowed psychomotor performance seen in this group of lead workers.

It is interesting that no abnormal fatigue was evident in lead workers in any psychomotor tests. Even in the vigilance task lead workers maintained consis- tent, if lower, performance over an extended period. Possibly lead workers sacrificed speed for accuracy to overcome some of their physiological limitations.

Lead workers showed impairment in the first two stages of memory; sensory store and short term memory. Both short term memory tests, the paired associates, and the Sternberg test showed the lead worker's deficits and from the results of the Sternberg test it was possible to determine that the apparent short term memory deficit was a true cognitive one in addition to problems of response. Sternberg's theory predicts that the slope of the line which describes the relation between memory set size and reaction time is an indicator of the relative increase in reaction time with each additional memory item and therefore reflects cognitive elements in the test such as encoding and item matching. ${ }^{24}$ By contrast, the intercept of the line is thought to be a measure of the motor or response aspects of the test. Such a separation between cognitive and motor aspects of the memory test allowed the conclusion that whereas performance of the memory test was contaminated by slowed responding, cognitive functions were also affected.

Consistent with information processing theory it would be expected that sensory store memory was impaired in lead workers if the visual stimulus was degraded at the first input level as shown by lowered CFF thresholds. Similarly, if sensory store memory is affected it can be argued that short term memory ought to be impaired as well due to inefficient processing of the information in the first memory stage. Applying this same reasoning, long term memory also should have been impaired in lead workers. The fact that it was not was probably due to the dependence of long term memory on prior learning or rehearsal and the fact that only the relatively few lead workers who initially learned the to be remembered material to criterion were included in the estimate of long term memory performance of lead workers. It appeared that once lead workers had learnt material, they were able to remember and retrieve it as well as controls at least for a retention period of 1.5 hours. Learning, however, seemed to be difficult for them.

It must be remembered that all lead workers were and virtually always had been below the threshold limit value for blood lead concentrations, yet most neuropsychological functions were clearly affected in the lead exposed group. Attempts to relate performance to measures of exposure, however, yielded only one significant association. It is possible that the lead workers in this study were a fairly homogeneous group with respect to blood lead and for this reason, the exposure measures fail to "explain" performance. In studies that have shown performance and exposure relations the range of blood lead concentrations was much wider than in the present study, particularly at 
the lower end. ${ }^{2526}$ In fact the threshold for effects has been shown to be as low as $1.45 \mu \mathrm{mol} / 1^{11}$ and $1.3 \mu \mathrm{mol} / 1$ for memory and learning functions ${ }^{10}$ which is lower than for any worker in this study.

In addition, even though its use is almost universal, some authors argue that blood lead is not a good indicator of biologically active lead and its effects on the nervous system. ${ }^{27} 28$

The results of this study add further weight to the conclusion that lead workers experience nervous system impairment at much lower blood lead concentrations than are currently regarded as "acceptable." They also show, however, that the particular effect of lead on the nervous system may be at the visual sensory level and that the findings of psychomotor and cognitive impairment in this and other studies may be confounded by visual sensory input problems.

We are indebted to Jan Sanderson for help in stimulus preparation and data collection and to Belinda Clarke for help in data analysis. The contribution of the staff from the heavy metals laboratory of the NSW Health Department's Division of Analytical Laboratories in analysis of blood is also gratefully acknowledged.

We are grateful to the acting director of the Division of Occupational Health, Dr B M Nolan, and the acting coordinator of the NSW Occupational Health, Safety and Rehabilitation Council, Dr F Rainsford, for permission to publish this paper.

Requests for reprints to: Dr A Williamson, Division of Occupational Health, PO Box 163, Lidcombe, NSW, Australia, 2141.

\section{References}

${ }^{1}$ Johnson BL, Burg JR, Xintaras C, Handke JL. A neurobehavioural examination of workers from a primary nonferrous smelter. Neurotoxicology 1979;1:561-81.

${ }^{2}$ Bordo BM, Filippini G, Massetto N, Musicco M, Boeri R. Electrophysiological study of subjects occupationally exposed to lead and with low levels of lead poisoning. Scand J Work Environ Health 1982;8(suppl 1):142-7.

${ }^{3}$ Repko JD, Morgan BB, Nicholson J. Behavioural effects of occupational exposure to lead. Washington DC: US Department of Health, Education and Welfare, 1975. (Publication No (NIOSH) 75-164).

${ }^{4}$ Repko JD, Corum CR, Jones PD, Garcia LS. The effects of inorganic lead on behavioural and neurological function. Final report. Washington DC: US Department of Health, Education and Welfare, 1978. (USDHEW (NIOSH) publication No 78-128.)

${ }^{5}$ Irwig LM, Harrison WO, Rocks P, Webster I, Andrew M. Lead and morbidity: a dose-response relationship. Lancet 1978;i:4-7.
${ }^{6}$ Grandjean P, Arnvig E, Beckmann J. Psychological dysfunctions in lead-exposed workers. Scand J Work Environ Health 1978;4:295-303.

${ }^{7}$ Hanninen $H$, Hernberg S, Mantere P, Vesanto R, Jalkanen M. Psychological performance of subjects with low exposure to lead. J Occup Med 1978;20:683-9.

${ }^{8}$ Arnvig E, Grandjean P, Beckmann J. Neurotoxic effects of heavy lead exposure determined with psychological tests. Toxicol Lett 1980;5:399-404.

${ }^{9}$ Valciukas JA, Lilis R, Eisinger J, Blumberg WE, Fischbein A, Selikoff IJ. Behavioural indicators of lead neurotoxicity: results of a clinical field survey. Int Arch Occup Environ Health 1978;41:217-36.

${ }^{10}$ Hogstedt C, Hane M, Agrell A, Bodin L. Neuropsychological test results and symptoms among workers with well defined longterm exposure to lead. Br J Ind Med 1983;40:99-105.

${ }^{11}$ Mantere P, Hanninen H, Hernberg S, Luukonen RA, Prospective follow-up study on psychological effects in workers exposed to low levels of lead. Scand J Work Environ Health 1984;10:43-50.

${ }^{12}$ Wechster DA. Wechster adult intelligence scale-revised. New York: Psychological Corporation, 1981.

${ }^{13}$ Wechster DA. A standardised memory scale for clinical use. J Psychol 1945;19:87-95.

${ }^{14}$ Hanninen $H$. Behavioural effects of occupational exposure to mercury and lead. In: Juuntunen J, ed. Occupational neurology. Helsinki: Institute of Occupational Health, 1983.

${ }^{15}$ Lindsay PH, Norman DA. Human information processing. New York: Academic Press, 1977.

${ }^{16}$ Williamson AM, Teo RKC, Sanderson J. Occupational mercury exposure and its consequences for behaviour. Int Arch Occup Environ Health 1982;50:273-86.

${ }^{17}$ Weber A, Jermini C, Grandjean EP. Relationship between objective and subjective assessment of experimentally produced fatigue. Ergonomics 1975;18:151-6.

${ }^{18}$ Weber A, Fussler C, O'Hanlon JF, Gierer R, Grandjean E. Psychophysical effects of repetitive tasks. Ergonomics 1980; 23:1033-46.

${ }^{19}$ Morgan CT. Physiological psychology. New York: McGraw Hill, 1965.

${ }^{20}$ Cavalleri A, Trimarchi F, Gelmi C. Effects of lead on the visual system of occupationally exposed subjects. Scand J Work Environ Health 1982;suppl 1:148-51.

${ }^{21}$ Wooller K, Melamed S. Simple tests for monitoring excessive lead absorption. Med J Aust 1978;1:163.

${ }^{22}$ Seppalainen AM, Hernberg S, Vesanto R, Kock B. Early neurotoxic effects of occupational lead exposure: a prospective study. Neurotoxicology 1983;4:181-92.

${ }^{23}$ Singer R, Valciukas J, Lilis R. Lead exposure and nerve conduction velocity: the differential time course of sensory and motor nerve effects. Neurotoxicology 1983;4:193-202.

${ }^{24}$ Sternberg S. Memory scanning: mental processes revealed by reaction-time experiments. Am Sci 1969;4:421-57.

${ }^{25}$ Campara P, D'Andrea F, Micciolo R, Savonitto C, Tansella M, Zimmerman-Tansella C. Psychological performance of workers with blood-lead concentration below the current threshold limit value. Int Arch Occup Environ Health 1984;53:233-46.

${ }^{26}$ Baker EL, Feldman RG, White RA, et al. Occupational lead neurotoxicity: a behavioural and electrophysiological evaluation. Study design and year one results. Br J Ind Med 1984;41:352-61.

${ }^{27}$ Waldron HA. The blood lead threshold. Arch Environ Health 1974;29:271-3.

${ }^{28}$ Lilis R, Fischbein A, Diamond S, et al. Lead effects among secondary lead smelter workers with blood lead levels below 80 micrograms/100 ml. Arch Environ Health 1977;32:256-66. 